\title{
In Quest of the Double Rotaxane Formation of the Bis(coronand) $(1,5),(2,4)-$ Durenetetrayl-bis(18-crown-5) with Organomagnesium Compounds
}

\author{
Gerard P. M. van Klink, ${ }^{[a]}$ Tateo Nomoto, ${ }^{[b]}$ Martin Lutz, ${ }^{[c]}$ Anthony L. Spek, ${ }^{[c]}$ \\ Otto S. Akkerman, ${ }^{[d]}$ and Friedrich Bickelhaupt*[d]
}

Keywords: Magnesium / Mercury / Chelates / Crown compounds

The interaction between the title compound, bis(coronand) 8 , and the diarylmagnesium compounds $\mathrm{Ph}_{2} \mathrm{Mg}$ and ( $p$ $\left.t \mathrm{BuC}_{6} \mathrm{H}_{4}\right)_{2} \mathrm{Mg}$ in diethyl ether leads to the formation of 1:2 complexes (9 and 10, respectively), irrespective of the initial ratio of the components. In $\left[\mathrm{D}_{8}\right]$ toluene, the three complex types can be discerned by ${ }^{1} \mathrm{H}$ NMR spectroscopy: double side-on (9a, 10a), side-on/rotaxane $(\mathbf{9 b}, \mathbf{1 0 b})$, and, to a very minor extent, double rotaxane $(\mathbf{9 c}, \mathbf{1 0 c})$. In the case of $\mathbf{1 0 a}$ and $\mathbf{1 0 b}$, the temperature dependence showed that rotaxane formation is enthalpically favored at the expense of a more negative entropy. As crystals suitable for structure determination could not be obtained from 9 and 10, the interaction of 8 with the sterically less demanding $\mathrm{Hg}(\mathrm{SCN})_{2}$ was studied. In this case, analogous pseudorotaxanes are formed exclusively, and both the 1:2 complex $\left[\mathbf{8} \cdot\left\{\mathrm{Hg}(\mathrm{SCN})_{2}\right\}_{2}\right](\mathbf{1 1})$ and its 1:1 analogue 12 were observed. The double rotaxane structure of 11 was confirmed by X-ray crystal structure determination.

(ㄷ) Wiley-VCH Verlag GmbH \& Co. KGaA, 69451 Weinheim, Germany, 2004)

\section{Introduction}

In most respects, crown ethers derived from $m$-xylene behave as normal ligands toward organomagnesium compounds. For instance, side-on complexes involving two crown ether oxygen atoms are formed, allowing magnesium to achieve its usual coordination number of four. ${ }^{[1]}$ However, a number of aspects unusual in the chemistry of organomagnesium compounds have also been encountered ${ }^{[1,2]} \mathrm{An}$ illustration is the high organolithium-like reactivity demonstrated by intra-annular metalation of $\mathbf{1}$ to $\mathbf{2}$ (Scheme 1) ${ }^{[3]}$ by metal-halogen exchange as in $\mathbf{3}$ to furnish $4{ }^{[3,4]}$ and by several ether cleavage reactions of substrates which are normally inert toward organomagnesium reagents. ${ }^{[2,5,6]}$

Another challenging aspect is the formation of organometallic rotaxanes ${ }^{[7,8]}$ such as $\mathbf{6}^{[1,2,9,10]}$ and even catenanes $7^{[11]}$ from 5 (Scheme 2). They are of interest not

[a] Department of Metal-Mediated Synthesis, Utrecht University, Padualaan 8

$3584 \mathrm{CH}$ Utrecht, The Netherlands

[b] Faculty of Education, Mie University, Tsu, Mie 514-8507, Japan

[c] Department of Crystal and Structural Chemistry, Utrecht University, Padualaan 8 ,

$3584 \mathrm{CH}$ Utrecht, The Netherlands

[d] Scheikundig Laboratorium, Vrije Universiteit,

De Boelelaan 1083, $1081 \mathrm{HV}$ Amsterdam, The Netherlands

Fax: (internat.) +31-20-4447488

E-mail: bicklhpt@few.vu.nl
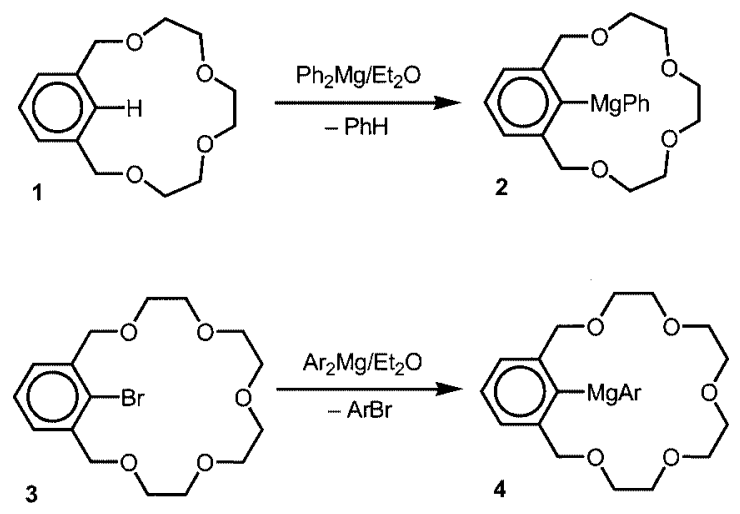

Scheme 1. Ar $=\mathrm{Ph}, p-t \mathrm{BuC}_{6} \mathrm{H}_{4}$

only in view of their remarkable structures, but also because of their mode of formation. The problem is that the crown ether cavity is too small to permit direct penetration by a benzene ring, so multistep processes that involve reversible ionic cleavage of a carbon-magnesium bond have to be postulated. ${ }^{[9-11]}$

In spite of the extensive literature on rotaxanes and catenanes in general, ${ }^{[12,13]}$ derivatives of organometallic compounds with multiple threading have not been reported yet. On the basis of the results briefly indicated above, it seemed of interest to extend our investigations to double rotaxanes or catenanes of organomagnesium compounds for two re- 

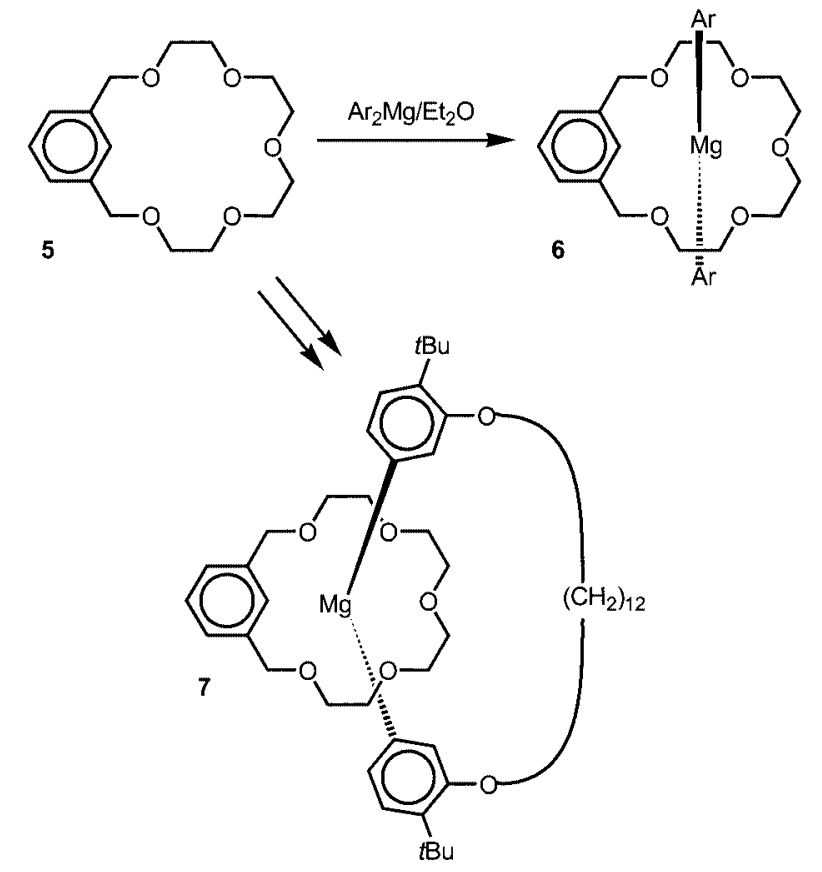

Scheme 2. $\mathrm{Ar}=\mathrm{Ph}, p-t \mathrm{BuC}_{6} \mathrm{H}_{4}$

asons: firstly, it was attractive to explore the transmission of conformational information between the different complexation sites, the so-called allosteric effect; ${ }^{[14-17]}$ and secondly, it was conceivable that one could construct higherorder assemblies of these complex types. A good starting point for such investigations appeared to be the title compound, the bis(coronand) 8 (Scheme 3), the synthesis of which has been described. ${ }^{[18]}$

\section{Results and Discussion}

\section{Complexation of 8 with Diarylmagnesium Compounds}

To study the interaction between $\mathbf{8}$ and diphenylmagnesium, diethyl ether solutions of the two compounds were mixed at room temperature in a molar ratio of 1:2. A homogeneous yellow solution resulted, but after a few minutes, a white precipitate formed. The supernatant solution was removed and hydrolyzed; it contained $10 \%$ diphenylmagnesium [according to the titration for $\mathrm{Mg}^{2+}$ and $\mathrm{OH}^{-}$(acid/
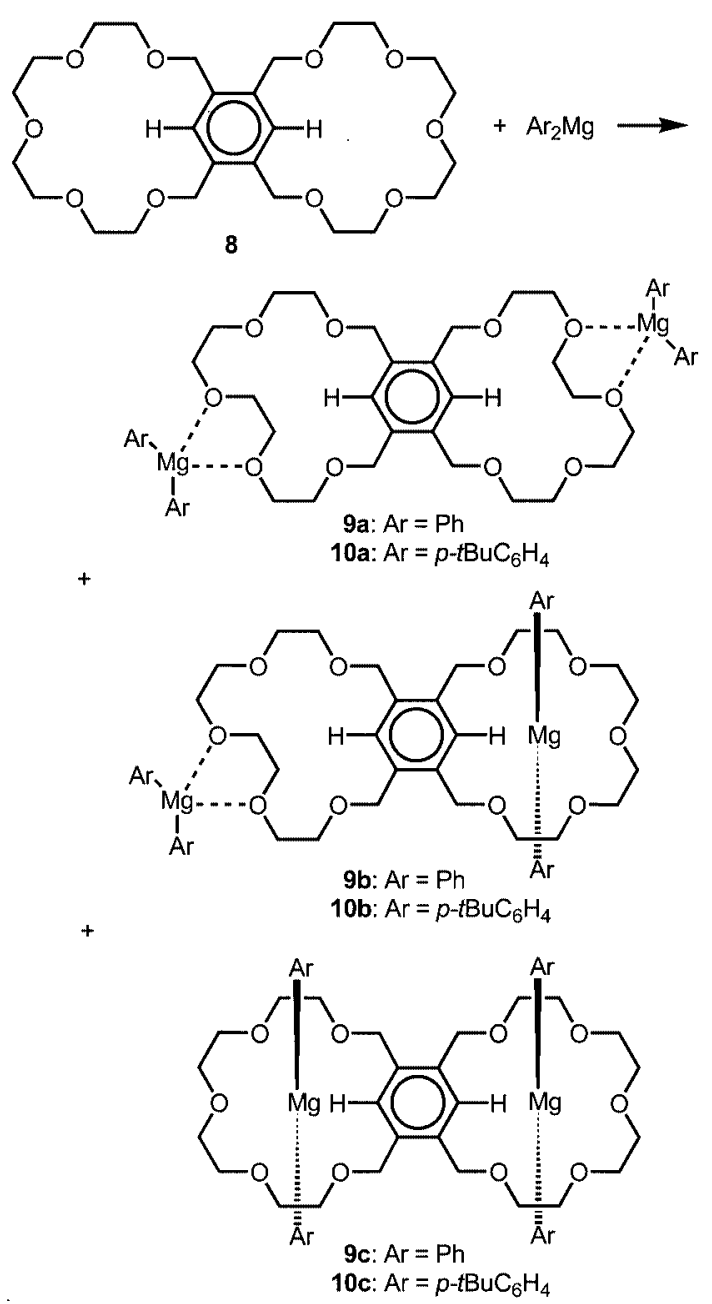

Scheme 3

base and EDTA) ${ }^{[19]}$ and no 8 ( ${ }^{1} \mathrm{H}$ NMR spectroscopy). From the precipitate, residual diethyl ether was removed by pumping under high vacuum; the resulting pale brown residue dissolved almost completely in $\left[\mathrm{D}_{8}\right]$ toluene. Hydrolysis of a sample followed by titration as mentioned above revealed the presence of $\mathbf{8}$ and of diphenylmagnesium in a ratio of 1:2. The ${ }^{1} \mathrm{H}$ NMR spectrum $(400 \mathrm{MHz})$ in $\left[\mathrm{D}_{8}\right]$ toluene was rather complex. It showed, amongst others, crown

Table 1. Chemical shifts of benzylic $\left(\mathrm{Ar}^{\prime} \mathrm{CH}_{2}\right)$ and arylic $\left(\mathrm{Ar}^{\prime} \mathrm{H}\right)$ protons in $\mathbf{8}$ and its complexes

\begin{tabular}{|c|c|c|c|c|c|c|}
\hline Compound & $\mathrm{Ar}^{\prime} \mathrm{CH}_{2}$ free & $\mathrm{Ar}^{\prime} \mathrm{CH}_{2}$ side-on & $\mathrm{Ar}^{\prime} \mathrm{CH}_{2}$ rotaxane & $\operatorname{Ar}^{\prime} H$ free & $\mathrm{Ar}^{\prime} H$ side-on & $\operatorname{Ar}^{\prime} H$ rotaxane \\
\hline $8^{[\mathrm{a}]}$ & 4.57 & - & - & 7.93 & - & - \\
\hline $8^{[\mathrm{b}]}$ & 4.67 & - & - & 7.69 & - & - \\
\hline $9 \mathrm{a}^{[\mathrm{a}]}$ & - & 4.50 & - & - & 7.83 & - \\
\hline $9 \mathbf{b}^{[\mathrm{a}]}$ & - & 4.47 & 4.20 & - & 7.74 & 8.60 \\
\hline $9 \mathrm{c}^{[\mathrm{a}]}$ & - & - & 4.09 & - & - & 8.56 \\
\hline $10 \mathbf{a}^{[\mathrm{a}]}$ & - & 4.52 & - & - & 7.89 & - \\
\hline $10 b^{[a]}$ & - & 4.49 & 4.23 & - & 7.89 & 8.67 \\
\hline $10 c^{[a]}$ & - & - & $4.08 ?$ & - & - & $?$ \\
\hline $11^{[\mathrm{b}]}$ & - & - & 4.78 & - & - & 8.05 \\
\hline $12^{[\mathrm{b}]}$ & 4.59 & - & 4.79 & 7.77 & - & 7.79 \\
\hline
\end{tabular}

${ }^{\text {[a] }}$ In $\left[\mathrm{D}_{8}\right]$ toluene. ${ }^{[\mathrm{b}]}$ In $\mathrm{CDCl}_{3}$. 
ether signals at about $\delta=4.2$ and $4.09 \mathrm{ppm}\left(\mathrm{Ar}^{\prime} \mathrm{CH}_{2}\right)$ and at $\delta=8.6 \mathrm{ppm}\left(\mathrm{Ar}^{\prime} \mathrm{H}\right.$; Table 1$)$.

These $\mathrm{Ar}^{\prime} \mathrm{CH}_{2}$ protons are shielded by about $0.4 \mathrm{ppm}$ and the corresponding crown ether methylene protons (see Exp. Sect.) by $0.4-0.5 \mathrm{ppm}$ are similar to those within 8 . Interestingly, the intra-annular aromatic xylylene protons $\operatorname{Ar}^{\prime} H$ are deshielded by $0.4 \mathrm{ppm}$. This is reminiscent of analogous behavior of aryl protons inside the cavity of small metacyclophanes; ${ }^{[20,21]}$ it has been ascribed to the van der Waals effect caused by steric congestion. ${ }^{[22]}$ As similar changes have also been observed for $6^{[9]}$ and $7,{ }^{[11]}$ these phenomena are indicative of the rotaxane-type threading of a diarylmagnesium into a $m$-xylylene crown ether cavity. In view of the 1:2 ratio of the two components, three structures are conceivable: the double side-on complex 9a, the sideon/rotaxane complex $\mathbf{9 b}$, and the double rotaxane complex 9c (Scheme 3).

Due to the complicated pattern and to partial overlap, it was difficult to assign all of the signals for the three complexes. However, based on the $\mathrm{Ar}^{\prime} \mathrm{CH}_{2}$ signals at $\delta=4.50$, $4.47,4.20$, and $4.09 \mathrm{ppm}$ with a relative intensity of $56: 21: 22: 1$, a tentative assignment was possible, which was supported by the intensities of the $\operatorname{Ar}^{\prime} H$ signals at $\delta=7.83$, $7.74,8.60$, and $8.56 \mathrm{ppm}$, the ratio of which is $\mathrm{Ar}^{\prime} \mathrm{CH}_{2} /$ $\operatorname{Ar}^{\prime} H=4: 1$. As the values of $\delta=4.50$ and $7.83 \mathrm{ppm}$ are very close to those of free $\mathbf{8}(\delta=4.57$ and $7.93 \mathrm{ppm})$, they must be assigned to 9a. Two other pairs of shifts at $\delta=$ 4.47 and $7.74 \mathrm{ppm}$ and $\delta=4.20$ and $8.60 \mathrm{ppm}$ have equal intensities which is in line with $\mathbf{9 b}$; this is further supported by the observation that the shifts of the first pair correspond to those of $\mathbf{9 a}$ indicating side-on coordination, while those for the second pair are typical for a rotaxane structure. ${ }^{[9,11]}$ The least certain assignment is that of the pair at $\delta=4.09$ and $8.56 \mathrm{ppm}$ due to the low intensity; it cannot be excluded that these signals are caused by impurities, but on the other hand, the 4:1 ratio and the typical "rotaxane shift range" support the tentative assignment to $9 c$.

An attempt to change the ratios of the three isomers by mixing 8 and diphenylmagnesium in diethyl ether in a 1:1 ratio was not successful. Again, a precipitate was formed. Analysis of the supernatant by titration and ${ }^{1} \mathrm{H}$ NMR spectroscopy (vide supra) showed it to contain only $\mathbf{8}$. The precipitate was dissolved in $\left[\mathrm{D}_{8}\right]$ toluene; the ${ }^{1} \mathrm{H}$ NMR spectrum was practically identical to that described above, i.e. a 1:2 ratio for the components 8 and diphenylmagnesium, and the same isomer pattern as for 9. This is remarkable insofar as the 1:2 complexes are apparently preferred even in the presence of an excess of the bis(coronand) 8 . It is unlikely that this is due to an allosteric effect; more likely, the low solubility of $\mathbf{9}$ shifts the equilibrium in its favor.

This low solubility also hampered the spectral analysis of 9. In an attempt to obtain more soluble complexes, we performed analogous experiments by mixing $\mathbf{8}$ with $\operatorname{di}(p-$ tert-butylphenyl)magnesium in diethyl ether, but in this case, too, precipitation occurred. After evaporation of the diethyl ether and dissolution in $\left[\mathrm{D}_{8}\right]$ toluene, ${ }^{1} \mathrm{H}$ NMR analysis (Table 1) revealed the presence of the double sideon complex 10a and of the side-on/rotaxane complex $\mathbf{1 0 b}$; the double rotaxane 10c could not be reliably identified, but a faint signal at $\delta=4.08 \mathrm{ppm}$ might be due to its $\mathrm{ArCH}_{2}$ protons. It is not surprising to find that the equilibrium between the two types of complexes is not strongly influenced by the remote tert-butyl group in 10; at $298 \mathrm{~K}$, the a/ b ratios are 56:43 for $\mathbf{9}$ and $64.5: 35.5$ for $\mathbf{1 0}$. According to the X-ray crystal structure of $6{ }^{[9]}$ one of the aryl rings is probably located partly above the aromatic ring of the crown ether; this could lead to increased steric hindrance in 10b as compared to $\mathbf{9 b}$ which explains the slightly higher preference for 10a.

As the solubility of $\mathbf{1 0}$ was somewhat higher than that of 9, we were able to check the temperature dependence of the ${ }^{1} \mathrm{H}$ NMR spectrum and its influence on the equilibrium between 10a and 10b. The results (Table 2) are not very reliable because a precipitate formed slowly in the NMR tube, especially at higher temperatures.

Table 2. Temperature dependence of isomer ratios 10a:10b

\begin{tabular}{llllll}
\hline$T[\mathrm{~K}]$ & 298 & 328 & 344 & 355 & 365 \\
\hline $\mathbf{1 0 a}^{[\mathrm{a}][\mathrm{b}]}$ & 64.5 & 70.7 & 73.5 & 82.1 & 88.9 \\
$\mathbf{1 0 b}^{[\mathrm{a}] \mathrm{b}]}$ & 35.5 & 29.3 & 26.5 & 17.9 & 11.1 \\
\hline
\end{tabular}

${ }^{[\mathrm{a}]}$ In $\left[\mathrm{D}_{8}\right]$ toluene. ${ }^{[\mathrm{b}]} \mathrm{In} \%$.

Raising the temperature shifts the equilibrium in favor of the major component 10a. On cooling down, this process is (slowly!) reversible. In view of the precipitate formation and the few data points, it is problematic to derive quantitative values for $\Delta H$ and $\Delta S$. However, at least a qualitative indication can be obtained if one neglects two dubious points (with more precipitate) at higher temperature. For the transformation $10 \mathrm{a} \rightarrow \mathbf{1 0 b}$, the three lower points give a very good linear correlation [Equation (1)], from which $\Delta H=-7.8 \mathrm{~kJ} \cdot \mathrm{mol}^{-1}$ and $\Delta S=-31 \mathrm{~J} \cdot \mathrm{mol}^{-1} \cdot \mathrm{K}^{-1}$ are obtained; inclusion of all 5 temperatures would lead to $\Delta H=$ $-19 \mathrm{~kJ} \cdot \mathrm{mol}^{-1}$ and $\Delta S=-66 \mathrm{~J} \cdot \mathrm{mol}^{-1} \cdot \mathrm{K}^{-1}(R=0.820)$.

$\Delta G=-7791+31.1 \cdot T(R=1.000)$

With appropriate caution, one may conclude that the transformation of a side-on complex to a rotaxane in the reaction $10 \mathrm{a} \rightarrow \mathbf{1 0 b}$ is slightly exothermic. This is reasonable if one considers that in 10a, the magnesium atom is coordinated to two oxygen atoms only, whereas the magnesium atom in the rotaxane cavity of $\mathbf{1 0 b}$ weakly interacts with additional oxygens as indicated by the $\mathrm{X}$-ray structures of 6 and analogous rotaxanes. ${ }^{[1,7-11]}$ As expected, the reaction entropy $\Delta S$ is negative because the rotaxane is conformationally more rigid than the side-on complex. Apparently, this additional rigidity overcompensates the gain in enthalpy in the transformation of the mono rotaxanes $\mathbf{b}$ to the double rotaxanes $\mathbf{c}$; consequently, $\mathbf{9 c}$ and $\mathbf{1 0 c}$ are minor components only. 


\section{Complexation of 8 with $\mathrm{Hg}(\mathrm{SCN})_{2}$}

As the double rotaxane formation between $\mathbf{8}$ and diarylmagnesium compounds turned out to be unfavorable, we investigated the interaction of $\mathbf{8}$ with $\mathrm{Hg}(\mathrm{SCN})_{2}$; the latter has served to study pseudorotaxane formation and allosteric effects in several crown ether systems. ${ }^{[17,23,24]}$ When solutions of 8 and of $\mathrm{Hg}(\mathrm{SCN})_{2}$ in acetone were mixed, a colorless precipitate was obtained. It was filtered off, dissolved in $\mathrm{CDCl}_{3}$, and analyzed by ${ }^{1} \mathrm{H}$ NMR spectroscopy (Table 1), which revealed the formation of a single symmetrical complex. The most conspicuous signal was at $\delta=$ $8.05 \mathrm{ppm}$; the deshielding of this proton relative to its counterpart in 8 ( $\delta=7.69 \mathrm{ppm} ; \Delta \delta=-0.36 \mathrm{ppm})$ is indicative of the intra-annular $\operatorname{Ar} H$ of a rotaxane structure (vide supra). The structural assignment of $\mathbf{1 1}$ (Scheme 4) is further supported by the equivalence of the two $\operatorname{Ar} H$ protons and the eight $\mathrm{ArCH}_{2}$ protons. Finally, the identity of 11 was proven by an X-ray crystal structure determination (Figure 1). As the crystals were obtained directly from the reaction mixture and could not be recrystallized due to de-

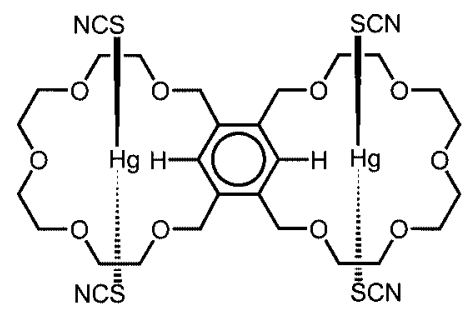

11

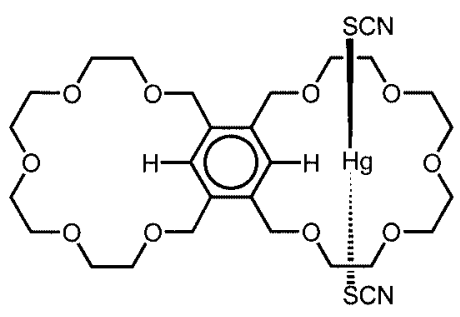

12

Scheme 4

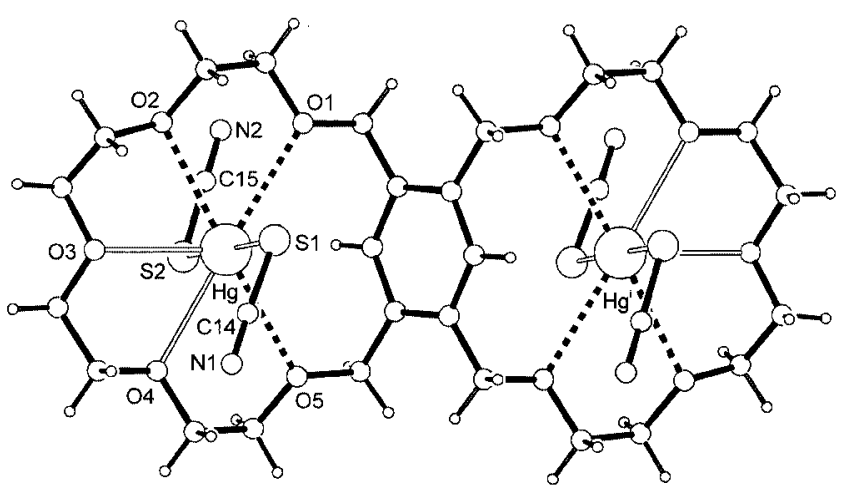

Figure 1. PLUTON ${ }^{[25]}$ projection of compound 11; symmetry operation $i: 1-x, 1-y, 1-z$; selected bond lengths $[\AA]$ : $\mathrm{Hg}-\mathrm{S} 1$ 2.358(4), Hg-S2 2.384(4), Hg-O3 2.737(13), Hg-O4 2.742(13), $\mathrm{Hg}-\mathrm{O} 12.925(12), \mathrm{Hg}-\mathrm{O} 2$ 2.824(12), Hg-O5 2.898(13) composition, the quality of this determination was not high $(R 1=0.0740)$; nevertheless, it unambiguously established the double pseudorotaxane threading of $\mathrm{Hg}(\mathrm{SCN})_{2}$ through 8.

Solutions of $\mathbf{1 1}$ in $\mathrm{CDCl}_{3}$ deteriorated on standing as evidenced by the appearance of several new signals in the ${ }^{1} \mathrm{H}$ NMR spectra. When 8 and $\mathrm{Hg}(\mathrm{SCN})_{2}$ were mixed in a $1: 1$ ratio, four $\operatorname{Ar} H$ signals were observed at $\delta=7.69,7.77$, 7.79 , and $8.05 \mathrm{ppm}$. Those at 7.69 and $8.05 \mathrm{ppm}$ stem from free $\mathbf{8}$ and 11, respectively. The two remaining signals are assigned to the mono pseudorotaxane $\mathbf{1 2}$. From the signal intensities, the following ratios were derived: 8:12:11 = 20:72:8, again showing a small bias against formation of the double pseudorotaxane (11) which, however, is less dramatic than in the case of $\mathbf{9 c}$ and $\mathbf{1 0 c}$. This may be ascribed to the fact that the linear $\mathrm{Hg}(\mathrm{SCN})_{2}$ causes fewer steric interactions inside the crown ether than the aryl groups of $\mathrm{Ar}_{2} \mathrm{Mg}$.

\section{Conclusion}

The interaction between the title bis(coronand) 8 and the diarylmagnesium compounds $\mathrm{Ph}_{2} \mathrm{Mg}$ and $\left(p-t \mathrm{BuC}_{6} \mathrm{H}_{4}\right)_{2} \mathrm{Mg}$ in diethyl ether results in the formation of 1:2 complexes $(\mathbf{9}$ and 10, respectively), irrespective of the initial ratio of the components; presumably, this is caused by the low solubility of 9 and 10. In $\left[\mathrm{D}_{8}\right]$ toluene, three types of complexes can be discerned by ${ }^{1} \mathrm{H}$ NMR spectroscopy: double side-on (9a, 10a), side-on/rotaxane $(\mathbf{9 b}, \mathbf{1 0 b})$, and, to a very minor extent, double rotaxane $(\mathbf{9 c}, \mathbf{1 0 c})$; the latter two occur in approximately $1 \%$ yield only and are the first examples of organometallic double rotaxanes. In the case of 10a and $\mathbf{1 0 b}$, the temperature dependence showed that rotaxane formation is enthalpically favored at the expense of a more negative entropy. Presumably, the formation of the double rotaxanes $9 \mathbf{c}$ and $\mathbf{1 0 c}$ is counteracted by interaction of the magnesium bound aryl groups across the central aromatic ring.

Due to the low solubility of $\mathbf{9}$ and $\mathbf{1 0}$, crystals suitable for structure determination could not be obtained. For this reason, the interaction of $\mathbf{8}$ with the sterically less demanding $\mathrm{Hg}(\mathrm{SCN})_{2}$ was studied. In this case, pseudorotaxanes are formed exclusively, and both the 1:2 complex $\left[\mathbf{8} \cdot\left\{\mathrm{Hg}(\mathrm{SCN})_{2}\right\}_{2}\right](\mathbf{1 1})$ and its 1:1 analogue $\mathbf{1 2}$ were observed by ${ }^{1} \mathrm{H}$ NMR spectroscopy. The double pseudorotaxane structure of $\mathbf{1 1}$ was confirmed by an X-ray crystal structure determination.

\section{Experimental Section}

General: All manipulations involving organomagnesium compounds were carried out in completely sealed glassware using standard high vacuum techniques. ${ }^{[19]}$ Amounts of 'total base' and magnesium in organomagnesium samples were determined, after hydrolysis of a sample, by titration with $\mathrm{HCl}\left(\mathrm{OH}^{-}\right)$and EDTA $\left(\mathrm{Mg}^{2+}\right)$, respectively. ${ }^{[19]}$ Solvents were dried by distillation from Li$\mathrm{AlH}_{4}$ after pre-drying over $\mathrm{NaOH}$. NMR spectra were recorded on 
a Bruker AC 200 spectrometer $\left({ }^{1} \mathrm{H}\right.$ NMR: $\delta=200.1 \mathrm{MHz} ;{ }^{13} \mathrm{C}$ NMR: $\delta=50.32 \mathrm{MHz}$ ) or on a Bruker MSL 400 spectrometer $\left({ }^{1} \mathrm{H}\right.$ NMR: $\delta=400.1 \mathrm{MHz} ;{ }^{13} \mathrm{C}$ NMR: $\left.\delta=100.6 \mathrm{MHz}\right)$. HRMS measurements were performed on a Finnigan MAT 90 spectrometer (direct inlet). Caution: Organomercury compounds are poisonous!

Diphenylmagnesium: Diphenylmercury $(6.39 \mathrm{~g}, 18 \mathrm{mmol})$ was stirred with doubly sublimed magnesium $(4.37 \mathrm{~g}, 180 \mathrm{mmol})$ in diethyl ether $(180 \mathrm{~mL})$ in a fully sealed glass system for three weeks. After the magnesium amalgam had settled, the clear solution was decanted into a second vessel, and an aliquot of known volume was hydrolyzed and titrated $\left(\mathrm{OH}^{-} \text {and } \mathrm{Mg}^{2+}\right)^{[19]}$ to establish the concentration of diphenylmagnesium.

Bis(p-tert-butylphenyl)magnesium: In a fully sealed glass system, bis(p-tert-butylphenyl)mercury $(9.34 \mathrm{~g}, 20 \mathrm{mmol})$ was stirred with doubly sublimed magnesium $(4.86 \mathrm{~g}, 200 \mathrm{mmol})$ in diethyl ether $(200 \mathrm{~mL})$ for three weeks. After settling of the magnesium amalgam, the clear solution was decanted into a second vessel, and an aliquot of known volume was hydrolyzed and titrated $\left(\mathrm{OH}^{-}\right.$and $\left.\mathrm{Mg}^{2+}\right)^{[19]}$ to establish the concentration of bis( $p$-tert-butylphenyl)magnesium.

Reaction of 8 with Two Molar Equivalents of Diphenylmagnesium: Solutions of $\mathbf{8}^{[18]}[7.55 \mathrm{mg}, 0.0147 \mathrm{mmol}$ in diethyl ether $(2 \mathrm{~mL})$ ] and of diphenylmagnesium [0.03 mmol in diethyl ether $(8 \mathrm{~mL})]$ were combined in a fully sealed glass system. Within $15 \mathrm{~min}$, the clear yellow solution decolorized, and a white precipitate was formed. After heating at $40{ }^{\circ} \mathrm{C}$ for $2 \mathrm{~h}$, the clear supernatant was carefully decanted. The diethyl ether mother liquor was hydrolyzed, and the aqueous phase was titrated $\left(\mathrm{OH}^{-}\right.$and $\left.\mathrm{Mg}^{2+}\right){ }^{[19]}$ This indicated that more than $90 \%$ of the $\mathrm{Ph}_{2} \mathrm{Mg}$ was contained in the precipitate. This titration sample was carefully extracted with benzene. The organic layers were combined, dried $\left(\mathrm{MgSO}_{4}\right)$, filtered, and the solvents evaporated to dryness. ${ }^{1} \mathrm{H}$ NMR spectroscopy revealed no signals that could be ascribed to starting material $\mathbf{8}$. The solid reaction product obtained by decantation was dried by pumping under high vacuum, and toluene $(10 \mathrm{~mL})$ was then added, upon which most of the solid dissolved. From the supernatant, a sample was taken for characterization by ${ }^{1} \mathrm{H}$ NMR spectroscopy in $\left[\mathrm{D}_{8}\right]$ toluene. To quantify the effects of complexation on the chemical shifts of the crown ether, a reference spectrum of pure 8 was measured under identical conditions. ${ }^{1} \mathrm{H}$ NMR spectroscopy revealed that signals of the free crown ether $\mathbf{8}$ were absent. Assignment of all signals was not possible due to overlap and the complexity of the spectrum. Integration of the benzylic proton signals was used to determine the following relative yields: 9a $(55.9 \%), 9 b(43.2 \%)$, and $9 \mathbf{c}(0.9 \%)$. 8: ${ }^{1} \mathrm{H}$ NMR $\left\{\left[\mathrm{D}_{8}\right]\right.$ toluene, $200.1 \mathrm{MHz}$, ref. $\mathrm{C}_{6} \mathrm{D}_{5} \mathrm{CD}_{2} H: \delta=$ $2.03 \mathrm{ppm}\}: \delta=3.43-3.51$ (br. s, $32 \mathrm{H}, \mathrm{CH}_{2}$ ), 4.57 (s, $8 \mathrm{H}, \mathrm{ArCH}_{2}$ ), 7.93 (s, $2 \mathrm{H}, \mathrm{ArH}) \mathrm{ppm} .{ }^{13} \mathrm{C}$ NMR $\left\{\left[\mathrm{D}_{8}\right]\right.$ toluene, $50.32 \mathrm{MHz}$, ref. $\left.\mathrm{C}_{6} \mathrm{D}_{5} \mathrm{CD}_{3}: \delta=20.40 \mathrm{ppm}\right\}: \delta=69.61\left(\mathrm{tt},{ }^{1} J=139.9,{ }^{2} J=4.2 \mathrm{~Hz}\right.$, $\left.4 \mathrm{C}, \mathrm{CH}_{2} \mathrm{O}\right), 71.00\left(\mathrm{t},{ }^{1} \mathrm{~J}=141.9 \mathrm{~Hz}, 4 \mathrm{C}, \mathrm{CH}_{2} \mathrm{O}\right), 71.05\left(\mathrm{t},{ }^{1} \mathrm{~J}=\right.$ $\left.139.9 \mathrm{~Hz}, 4 \mathrm{C}, \mathrm{CH}_{2} \mathrm{O}\right), 71.18\left(\mathrm{td},{ }^{1} \mathrm{~J}=140.4,{ }^{3} \mathrm{~J}=3.8 \mathrm{~Hz}, 4 \mathrm{C}\right.$, $\left.\mathrm{ArCH}_{2}\right), 71.46\left(\mathrm{tt},{ }^{1} \mathrm{~J}=140.0,{ }^{2} \mathrm{~J}=2.5 \mathrm{~Hz}, 4 \mathrm{C}, \mathrm{CH}_{2} \mathrm{O}\right), 128.22(\mathrm{~d}$, ${ }^{1} J=163.8 \mathrm{~Hz}, 2 \mathrm{C}$, aryl-CH), $135.50\left(\mathrm{~d},{ }^{2} J=3.5 \mathrm{~Hz}, 2 \mathrm{C}\right.$, arylC) ppm.

9a: ${ }^{1} \mathrm{H}$ NMR $\left\{\left[\mathrm{D}_{8}\right]\right.$ toluene, $200.1 \mathrm{MHz}$, ref. $\mathrm{C}_{6} \mathrm{D}_{5} \mathrm{CD}_{2} H: \delta=$ $2.03 \mathrm{ppm}\}: \delta=3.38$ (s br., $\left.16 \mathrm{H}, \mathrm{CH}_{2}\right), 3.41\left(\mathrm{~m}, 16 \mathrm{H}, \mathrm{CH}_{2}\right), 4.50$ (s, $\left.8 \mathrm{H}, \mathrm{ArCH}_{2}\right), 7.24-7.26[\mathrm{~m}, \mathrm{ArH}(4)], 7.34$ [t br., $J=6.9 \mathrm{~Hz}$, $\operatorname{ArH}(3.5)$ ], 7.83 (s, $2 \mathrm{H}$, xylyl-H), 8.11 [d br., ${ }^{3} J=6.2 \mathrm{~Hz}$, $\operatorname{ArH}(2.6)] \mathrm{ppm}$.

9b: ${ }^{1} \mathrm{H}$ NMR $\left\{\left[\mathrm{D}_{8}\right]\right.$ toluene, $200.1 \mathrm{MHz}$, ref. $\mathrm{C}_{6} \mathrm{D}_{5} \mathrm{CD}_{2} \mathrm{H}: \delta=$ $2.03 \mathrm{ppm}\}: \delta=2.94-3.01\left(\mathrm{~m}, 4 \mathrm{H}, \mathrm{CH}_{2}\right), 3.12-3.16(\mathrm{~m}, 4 \mathrm{H}$, $\mathrm{CH}_{2}$ ), 3.30-3.34 (m, $\left.4 \mathrm{H}, \mathrm{CH}_{2}\right), 4.20$ [s, $4 \mathrm{H}, \mathrm{ArCH}_{2}$ (rotaxane)],
4.47 [s, $4 \mathrm{H}, \mathrm{ArCH}_{2}$ (side-on)], 7.10-7.14 [m, $\mathrm{ArH}(4)$ (rotaxane)], $7.22[\mathrm{t}, J=7.1 \mathrm{~Hz}, \operatorname{ArH}(3.5)], 7.80\left[\mathrm{~d},{ }^{3} J=6.4 \mathrm{~Hz}, \operatorname{ArH}(2.6)\right], 7.74$ [s, $1 \mathrm{H}$, xylyl-H (side-on)], 8.60 [s, $1 \mathrm{H}$, xylyl-H (rotaxane)] ppm. The other signals coincide with those of $9 \mathbf{a}$.

9c: ${ }^{1} \mathrm{H}$ NMR $\left\{\left[\mathrm{D}_{8}\right]\right.$ toluene, $200.1 \mathrm{MHz}$, ref. $\mathrm{C}_{6} \mathrm{D}_{5} \mathrm{CD}_{2} H: \delta=$ $2.03 \mathrm{ppm}\}: \delta=4.09\left(\mathrm{~s}, 8 \mathrm{H}, \mathrm{ArCH}_{2}\right), 8.56(\mathrm{~s}, 2 \mathrm{H}$, xylyl-H) ppm. The other signals coincide with those of $9 \mathbf{a}$ and $\mathbf{9 b}$.

Reaction of 8 with One Molar Equivalent of Diphenylmagnesium: Solutions of $8(7.55 \mathrm{mg}, 0.0147 \mathrm{mmol})$ in diethyl ether $(2 \mathrm{~mL})$ and of diphenylmagnesium [0.015 $\mathrm{mmol}$ in diethyl ether $(4 \mathrm{~mL})]$ were combined in a fully sealed glass system. After formation of a white suspension, the diethyl ether was distilled off and replaced by toluene $(10 \mathrm{~mL})$. The clear supernatant was decanted and analyzed by titration and by ${ }^{1} \mathrm{H}$ NMR spectroscopy in $\left[\mathrm{D}_{8}\right]$ toluene, which showed that only the starting material $\mathbf{8}$ was present. The pale brown precipitate was dissolved in $\left[\mathrm{D}_{8}\right]$ toluene and showed essentially the same ${ }^{1} \mathrm{H}$ NMR spectrum as that obtained in the reaction of $\mathbf{8}$ with two equivalents of $\mathrm{Ph}_{2} \mathrm{Mg}$, but with the products $9 \mathbf{a}$ and 9b in a ratio of 55:45. ${ }^{1} \mathrm{H}$ NMR signals of $9 \mathbf{c}$ were not detected.

Reaction of 8 with Two Molar Equivalents of $\left(p-t \mathrm{BuC}_{6} \mathrm{H}_{4}\right)_{2} \mathrm{Mg}$ : A solution of $\left(p-t \mathrm{BuC}_{6} \mathrm{H}_{4}\right)_{2} \mathrm{Mg}(0.085 \mathrm{mmol})$ in diethyl ether $(1 \mathrm{~mL})$ was added to $8(0.02167 \mathrm{~g}, 0.0421 \mathrm{mmol})$ in a fully sealed glass system, to give a clear yellow solution. After $10 \mathrm{~min}$, a finely divided powder started to precipitate. After $2.5 \mathrm{~h}$, the diethyl ether was distilled off, and toluene $(10 \mathrm{~mL})$ was added to the residue. The mixture was heated, but a clear solution was not obtained. Several attempts to crystallize the white residue in order to obtain suitable crystals for an X-ray crystal structure determination were unsuccessful. A sample was analyzed by ${ }^{1} \mathrm{H}$ NMR spectroscopy in $\left[\mathrm{D}_{8}\right]$ toluene. Assignment of all signals was not possible due to the complex nature of the spectrum. The two complexes in a mixture of 10a and 10b were present in a ratio of 64.5:35.5. In this case, only a faint signal of the double rotaxane complex 10c was discernible at $\delta=4.08 \mathrm{ppm}$.

10a: ${ }^{1} \mathrm{H}$ NMR $\left\{\left[\mathrm{D}_{8}\right]\right.$ toluene, $400.1 \mathrm{MHz}$, ref. $\mathrm{C}_{6} \mathrm{D}_{5} \mathrm{CD}_{2} H: \delta=$ $2.03 \mathrm{ppm}\}: \delta=1.36(\mathrm{~s}, 36 \mathrm{H}, t \mathrm{Bu}), 3.37-3.45\left(\mathrm{~m}, 32 \mathrm{H}, \mathrm{CH}_{2}\right)$, $4.52\left(\mathrm{~s}, 8 \mathrm{H}, \mathrm{ArCH}_{2}\right), 7.45\left[\mathrm{~d}, \mathrm{AB},{ }^{3} \mathrm{~J}=8 \mathrm{~Hz}, 8 \mathrm{H}, \mathrm{ArH}(3.5)\right], 7.89$ (s, $2 \mathrm{H}$, xylyl-H), 8.11 [d, BA, $\left.{ }^{3} J=8 \mathrm{~Hz}, 8 \mathrm{H}, \operatorname{ArH}(2.6)\right]$.

10b: ${ }^{1} \mathrm{H}$ NMR $\left\{\left[\mathrm{D}_{8}\right]\right.$ toluene, $400.1 \mathrm{MHz}$, ref. $\mathrm{C}_{6} \mathrm{D}_{5} \mathrm{CD}_{2} H: \delta=$ $2.03 \mathrm{ppm}\}: \delta=1.39(\mathrm{~s}, 18 \mathrm{H}, t \mathrm{Bu}) 2.93-2.99\left(\mathrm{~m}, 4 \mathrm{H}, \mathrm{CH}_{2}\right)$, $3.11-3.12\left(\mathrm{~m}, 4 \mathrm{H}, \mathrm{CH}_{2}\right), 3.17-3.23\left(\mathrm{~m}, 4 \mathrm{H}, \mathrm{CH}_{2}\right), 3.32-3.36$ (m, $4 \mathrm{H}, \mathrm{CH}_{2}$ ), 4.23 [s, $4 \mathrm{H}, \mathrm{ArCH}_{2}$ (rotaxane)], 4.49 [s, $4 \mathrm{H}, \mathrm{ArCH}_{2}$ (side-on)], 7.27 [d, AB, $\left.{ }^{3} J=7.9 \mathrm{~Hz}, 4 \mathrm{H}, \mathrm{ArH}(3.5)\right], 7.77$ [d, BA, $\left.{ }^{3} J=7.9 \mathrm{~Hz}, 4 \mathrm{H}, \operatorname{ArH}(2.6)\right], 7.89$ [s, $1 \mathrm{H}$, xylyl-H (side-on)], 8.67 [s, $1 \mathrm{H}$, xylyl-H (rotaxane)] ppm. The other signals overlap with those of 10a.

Reaction of 8 with Two Molar Equivalents of $\mathrm{Hg}(\mathrm{SCN})_{2}$ : A solution of $\mathrm{Hg}(\mathrm{SCN})_{2}(0.06335 \mathrm{~g}, 0.200 \mathrm{mmol})$ in acetone $(2 \mathrm{~mL})$ was added to a solution of $8(0.05143 \mathrm{~g}, 0.100 \mathrm{mmol})$ in acetone $(2 \mathrm{~mL})$. Within a few minutes, a white precipitate formed, which was separated by filtration and characterized by ${ }^{1} \mathrm{H}$ NMR spectroscopy as $\left[\mathbf{8} \cdot\left\{\mathrm{Hg}(\mathrm{SCN})_{2}\right\}_{2}\right](\mathbf{1 1})$; this assignment was confirmed by the X-ray crystal structure determination.

11: ${ }^{1} \mathrm{H}$ NMR $\left(\mathrm{CDCl}_{3}, 200.1 \mathrm{MHz}\right.$, ref. $\left.\mathrm{CHCl}_{3}: \delta=7.27 \mathrm{ppm}\right): \delta=$ 3.67 (s br., $\left.24 \mathrm{H}, \mathrm{CH}_{2}\right), 3.82\left(\mathrm{~m}, 8 \mathrm{H}, \mathrm{CH}_{2}\right), 4.78$ (s, $8 \mathrm{H}, \mathrm{ArCH}_{2}$ ), 8.05 (s, $2 \mathrm{H}, \mathrm{ArH}) \mathrm{ppm} .{ }^{13} \mathrm{C} \mathrm{NMR}\left(\mathrm{CDCl}_{3}, 100.6 \mathrm{MHz}\right.$, ref. $\left.\mathrm{CDCl}_{3}: \delta=77.00 \mathrm{ppm}\right): \delta=69.20\left(\mathrm{t},{ }^{1} J=145.6 \mathrm{~Hz}, 4 \mathrm{C}, \mathrm{CH}_{2}\right)$, $69.42\left(\mathrm{t},{ }^{1} J=139.7 \mathrm{~Hz}, 4 \mathrm{C}, \mathrm{CH}_{2}\right), 69.74\left(\mathrm{t},{ }^{1} J=142.7 \mathrm{~Hz}, 4 \mathrm{C}\right.$, $\left.\mathrm{CH}_{2}\right), 69.84\left(\mathrm{t},{ }^{1} \mathrm{~J}=141.9 \mathrm{~Hz}, 4 \mathrm{C}, \mathrm{CH}_{2}\right), 71.06\left(\mathrm{t},{ }^{1} \mathrm{~J}=140.3 \mathrm{~Hz}\right.$, 4C, $\mathrm{ArCH}_{2}$ ), 135.72 (d, ${ }^{2} J=44.8 \mathrm{~Hz}, 2 \mathrm{C}$, aryl-CH), 137.69 (br. s, $4 \mathrm{C}$, aryl-C) ppm. Contrary to $\mathbf{1 2}$ (vide infra), $\mathbf{1 1}$ was not volatile under DCI conditions. 
Reaction of 8 with One Molar Equivalent of $\mathrm{Hg}(\mathrm{SCN})_{2}$ : A solution of $\mathrm{Hg}(\mathrm{SCN})_{2}(0.03168 \mathrm{~g}, 0.100 \mathrm{mmol})$ in acetone $(2 \mathrm{~mL})$ was added to a solution of $8(0.05143 \mathrm{~g}, 0.100 \mathrm{mmol})$ in acetone $(2 \mathrm{~mL})$. The mixture slowly became turbid and after one hour, the organic solvent was evaporated to dryness. The residue was dissolved in $\mathrm{CDCl}_{3}$ and analyzed by ${ }^{1} \mathrm{H}$ NMR spectroscopy: 8 (21\%), $11(8 \%)$, and $12(72 \%)$.

12: ${ }^{1} \mathrm{H} \mathrm{NMR}\left(\mathrm{CDCl}_{3}, 200.1 \mathrm{MHz}\right.$, ref. $\left.\mathrm{CHCl}_{3}: \delta=7.27 \mathrm{ppm}\right): \delta=$ 3.65 (s br., $\left.12 \mathrm{H}, \mathrm{CH}_{2}\right), 3.72-3.77\left(\mathrm{~m}, 20 \mathrm{H}, \mathrm{CH}_{2}\right), 4.59$ [s, $4 \mathrm{H}$, $\mathrm{ArCH}_{2}$ (rotaxane)], 4.79 [s, $4 \mathrm{H}, \mathrm{ArCH}_{2}$ (free)], 7.77 (s, $1 \mathrm{H}, \mathrm{ArH}$ ), $7.79(\mathrm{~s}, 1 \mathrm{H}, \mathrm{ArH}) \mathrm{ppm}$. MS (DCI, $\left.\mathrm{NH}_{3}\right): m / z(\%)=850(10)[\mathrm{M}$ $\left.+\mathrm{NH}_{4}\right]^{+}, 791$ (7) $\left[\mathrm{M}+\mathrm{NH}_{4}-\mathrm{HSCN}\right]^{+}, 632$ (14), 591 (100).

X-ray Crystallographic Study: $\mathrm{C}_{30} \mathrm{H}_{42} \mathrm{Hg}_{2} \mathrm{~N}_{4} \mathrm{O}_{10} \mathrm{~S}_{4}$, (1148.10), colorless needles, $0.38 \times 0.15 \times 0.05 \mathrm{~mm}^{3}$, triclinic, $P \overline{1}$ (no. 2 ), $a=$ 7.3747(4), $b=10.0516(16), c=14.593(3) \AA, a=89.817(15), \beta=$ 78.769(10), $\gamma=77.999(9)^{\circ}, \quad V=1037.0(3) \AA^{3}, Z=1, \rho_{\mathrm{x}}=$ $1.838 \mathrm{gcm}^{-3}, 4716$ measured reflections, 3633 unique reflections $\left(R_{\mathrm{int}}=0.044\right) .161$ refined parameters, $\mathrm{R}$ (obsd. refl.): $R 1=0.0740$, $w R 2=0.2058$. $\mathrm{R}$ (all data): $R 1=0.0868, w R 2=0.2188$, GooF $=$ 1.055. Intensities were measured on a Enraf-Nonius CAD4T diffractometer with a rotating anode $\left(\right.$ Mo- $K_{\alpha}, \lambda=0.71073 \AA$ ) at a temperature of $150 \mathrm{~K}$. Reflection profiles for the best available crystal were structured, indicating a low quality crystal. An absorption correction was applied (program PLATON, ${ }^{[25]}$ routine DELABS, $\mu=7.647 \mathrm{~mm}^{-1}, 0.27-0.69$ transmission). The structure was solved with Patterson methods using the program DIRDIF97,[26] and refined with the program SHELXL-97[27] against $F^{2}$ of all reflections up to a resolution of $(\sin / \lambda)_{\max }=0.59 \AA^{-1}$. $\mathrm{Hg}$ and $\mathrm{O}$ atoms and the SCN ligand were refined freely with anisotropic displacement parameters; all other carbon atoms were refined with isotropic displacement parameters. Hydrogen atoms were refined as rigid groups. The drawings, structure calculations, and checking for higher symmetry were performed with the program PLATON. ${ }^{[25]}$

CCDC-213566 contains the supplementary crystallographic data for this paper. These data can be obtained free of charge at www.ccdc.cam.ac.uk/conts/retrieving.html [or from the Cambridge Crystallographic Data Centre, 12, Union Road, Cambridge CB2 1EZ, UK; Fax: (internat.) +44-1223-336-033; E-mail: deposit@ccdc.cam.ac.uk].

\section{Acknowledgments}

Dr. B. L. M. van Baar is gratefully acknowledged for performing the HRMS and DCI measurements and Dr. F. J. J. de Kanter for the NMR experiments. This work was supported in part (M. L., A. L. S.) by The Netherlands Foundation for Chemical Sciences (CW) with financial aid from the Netherlands Organization for Scientific Research (NWO).

${ }^{[1]}$ F. Bickelhaupt in Grignard Reagents, New Developments (Ed.: H. G. Richey, Jr.), Wiley, Chichester, 2000, chapter 9.
${ }^{[2]}$ F. Bickelhaupt, Acta Chem. Scand. 1992, 46, 409-417.

[3] P. R. Markies, T. Nomoto, O. S. Akkerman, F. Bickelhaupt, W. J. J. Smeets, A. L. Spek, Angew. Chem. 1988, 100, 1143-1144; Angew. Chem. Int. Ed. Engl. 1988, 27, 1084.

[4] P. R. Markies, T. Nomoto, G. Schat, O. S. Akkerman, F. Bickelhaupt, W. J. J. Smeets, A. L. Spek, Organometallics 1991, 10, 3826-3837.

[5] P. R. Markies, O. S. Akkerman, F. Bickelhaupt, W. J. J. Smeets, A. L. Spek, J. Am. Chem. Soc. 1988, 110, 4284-4292.

[6] G. J. M. Gruter, G. P. M. van Klink, O. S. Akkerman, F. Bickelhaupt, Organometallics 1993, 12, 1180-1188.

[7] H. G. Richey, Jr., D. M. Kushlan, J. Am. Chem. Soc. 1987, 109, 2510-2512.

${ }^{[8]}$ A. D. Pajerski, G. L. Bergstresser, M. Parvez, H. G. Richey, Jr., J. Am. Chem. Soc. 1988, 110, 4844-4845.

[9] P. R. Markies, T. Nomoto, O. S. Akkerman, F. Bickelhaupt, W. J. J. Smeets, A. L. Spek, J. Am. Chem. Soc. 1988, 110, $4845-4846$

${ }^{[10]}$ P. R. Markies, O. S. Akkerman, F. Bickelhaupt, W. J. J. Smeets, A. L. Spek, Organometallics 1994, 13, 2616-2627.

${ }^{[11]}$ G. J. M. Gruter, F. J. J. de Kanter, P. R. Markies, T. Nomoto, O. S. Akkerman, F. Bickelhaupt, J. Am. Chem. Soc. 1993, $115,12179-12180$.

${ }^{[12]}$ F. M. Raymo, J. F. Stoddart, Chem. Rev. 1999, 99, 1643-1663.

${ }^{[13]}$ J. W. Steed, J. L. Atwood, Supramolecular Chemistry, Wiley, Chichester, 2000, chapter 7.6.

${ }^{[14]}$ J. Rebek, Jr., Acc. Chem. Res. 1984, 17, 258-264.

${ }^{[15]}$ J. Rebek, Jr., T. Costello, L. Marshal, R. Wattley, R. C. Gadwood, K. Onan, J. Am. Chem. Soc. 1985, 107, 7481-7487.

${ }^{[16]}$ Y. Rubin, K. Dick, F. Diederich, T. M. Georgiedis, J. Org. Chem. 1986, 51, 3270-3278.

[17] A. M. Costero, M. Pitarch, C. Andreu, L. E. Orchando, J. M. Amigó, T. Debaerdemaeker, Tetrahedron 1996, 52, 669-676.

${ }^{[18]}$ G. P. M. van Klink, T. Nomoto, E. van Wees, A. G. L. Ostheimer, O. S. Akkerman, F. Bickelhaupt, SYNLETT 1996, $430-432$.

[19] A. D. Vreugdenhil, C. Blomberg, Recl. Trav. Chim. Pays-Bas 1963, $82,453-460$.

${ }^{[20]}$ S. Hirano, H. Hara, T. Hiyama, S. Fujita, H. Nozaki, Tetrahedron 1975, 31, 2219-2227.

[21] J. W. van Straten, W. H. de Wolf, F. Bickelhaupt, Tetrahedron Lett. 1977, 18, 4667-4670.

${ }^{[22]}$ L. M. Jackman, S. Sternhell, Applications of Nuclear Magnetic Resonance Spectroscopy in Organic Chemistry, 2nd ed., Pergamon Press, Oxford, 1969, p. 71-72.

${ }^{[23]}$ J. D. Owen, J. Chem. Soc., Dalton Trans. 1978, 1418-1423.

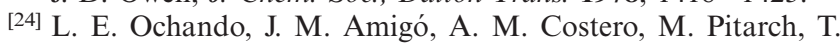
Debaerdemaeker, Cryst. Res. Technol. 1996, 31, 37-42.

${ }^{[25]}$ A. L. Spek, J. Appl. Cryst. 2003, 36, 7-13.

${ }^{[26]}$ P. T. Beurskens, G. Admiraal, G. Beurskens, W. P. Bosman, S. Garcia-Granda, R. O. Gould, J. M. M. Smits, C. Smykalla, The DIRDIF97 program system, Technical Report of the Crystallography Laboratory, University of Nijmegen, The Netherlands, 1997.

[27] G. M. Sheldrick, SHELXL-97, Program for crystal structure refinement, University of Göttingen, Germany, 1997.

Received July 3, 2003

Early View Article

Published Online October 23, 2003 